\title{
EXPERIMENTAL INVESTIGATION OF A CONCEPT WAVE ENERGY CONVERTER FOR HARNESSING LOW AMPLITUDE SEA WAVES
}

\author{
OLAKUNLE KAYODE* ${ }^{*}$, TITUS OLUWASUJI AJEWOLE ${ }^{2}$, OLUFEMI \\ ADEBOLA KOYA ${ }^{3}$ \\ ${ }^{1}$ Department of Mechanical Engineering, Osun State University, PMB 4494, Osogbo, \\ Nigeria \\ ${ }^{2}$ Department of Electrical and Electronic Engineering, Osun State University, Osogbo, \\ Nigeria \\ ${ }^{3}$ Department of Mechanical Engineering, Obafemi Awolowo University, Ile-Ife, Nigeria
}

\begin{abstract}
This paper presents the results from experimental validation of numerical simulation of a concept wave energy converter for low amplitude sea waves. The device was conceived to contain a wave amplifying device (WAD) to magnify the wave height of incident waves while point absorber buoy(s) efficiently harness the wave energy for electricity production. The validation results show that the optimum aperture angle for the WAD is $45 \pm 2$ degree, and wave height magnification of $170 \%$ is possible. The optimal buoy shape for the device was confirmed as concave wedge buoy. The combination of the two in a single device shall make economical the harnessing of low amplitude waves.
\end{abstract}

Keywords: wave energy converter, wave amplifying device, low amplitude waves

\section{INTRODUCTION}

Interest in renewable energy sources is growing due to a variety of factors; some of which included but not limited to rising price of refining fossil fuels, concern over their eventual depletion, greenhouse gasses emissions with its attendant negative impact on the global climate, as well as general environmental pollution associated with this source of energy. Researchers world over are actively investigating alternative energy sources to reduce at least, and to eliminate at most, over dependence on non-renewable fossils fuels. One of such renewable energy sources being investigated is sea wave energy. Sea waves advantages over other renewable energy sources such as solar and wind is its relative predictability and consistency when compared with them. Although the resources can vary a bit seasonally at a given location, on a day to day basis, the resource is relatively constant.

The best wave energy climates globally, whose annual average power levels are between 20 and $70 \mathrm{~kW} / \mathrm{m}$ or higher, are found in zones between 30 to $60^{\circ}$ of latitude [1] and less power levels outside these regions (Figure 1). The main reason for the better wave climates for the regions within 30 to $60^{\circ}$ latitudes in the north and the south hemispheres is due to the prevailing western winds in these regions which blow strongest in the winter. In most tropical waters, the average wave-power level is below $20 \mathrm{~kW} / \mathrm{m}$. Although mean annual wave power is comparatively lesser in the tropical region (between Lat $20^{\circ} \mathrm{N}$ and Lat. $20^{\circ} \mathrm{S}$ ) these is compensated for by lesser seasonal power variability [2]. Comparing Figure 1 with Figure 2 which shows the location of active wave energy

\footnotetext{
* Corresponding author, email: olakunle.kayode@uniosun.edu.ng

(C) 2020 Alma Mater Publishing House
} 
research sites globally indicated that the research focus is still mainly on the high energy latitude regions especially in Europe, North America and Australia.

Considering the offshore tropical water off the West African coast, a United Nations Environment Programme report [3] stated that studies shows that the region has the potential annual wave energy of 300 megawatt hours per meter of wave crest which is far below the highest reading of 535 for the North.

Atlantic Ocean (latitude 30 to $60^{\circ} \mathrm{N}$ ). Based on this, the report concluded that the future of wave energy in West African region was not encouraging, unless a process is developed that can favorably utilize relatively small and irregular wave formations of the region. The available wave power density, $\mathrm{P}\left(\mathrm{Wm}^{-1}\right)$, in each meter of wave crest length is given [4], as:

$$
P=500 H_{S}^{2} T_{e}
$$

where $\mathrm{H}_{\mathrm{S}}$ is the significant wave height and $\mathrm{T}_{\mathrm{e}}$ is the mean wave period.It is significant to note that wave power varies with the square of wave height. The implication of this is that when wave height is double, it generates four times as much power.

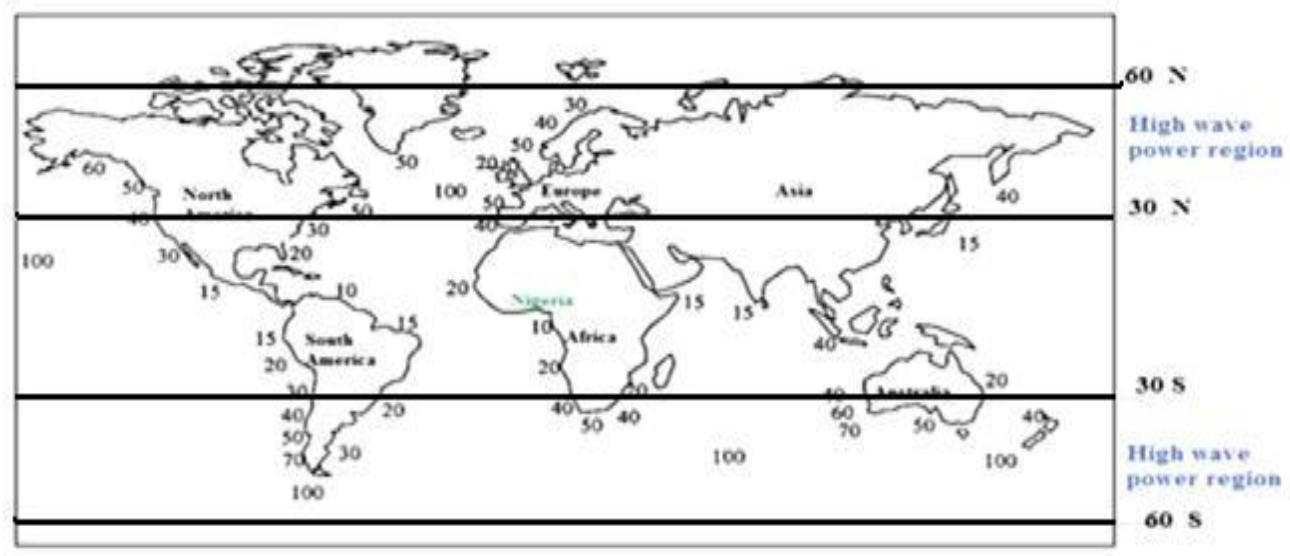

Fig. 1. The world wave energy resources (in $\mathrm{kW} / \mathrm{m}$ ) [5-7].

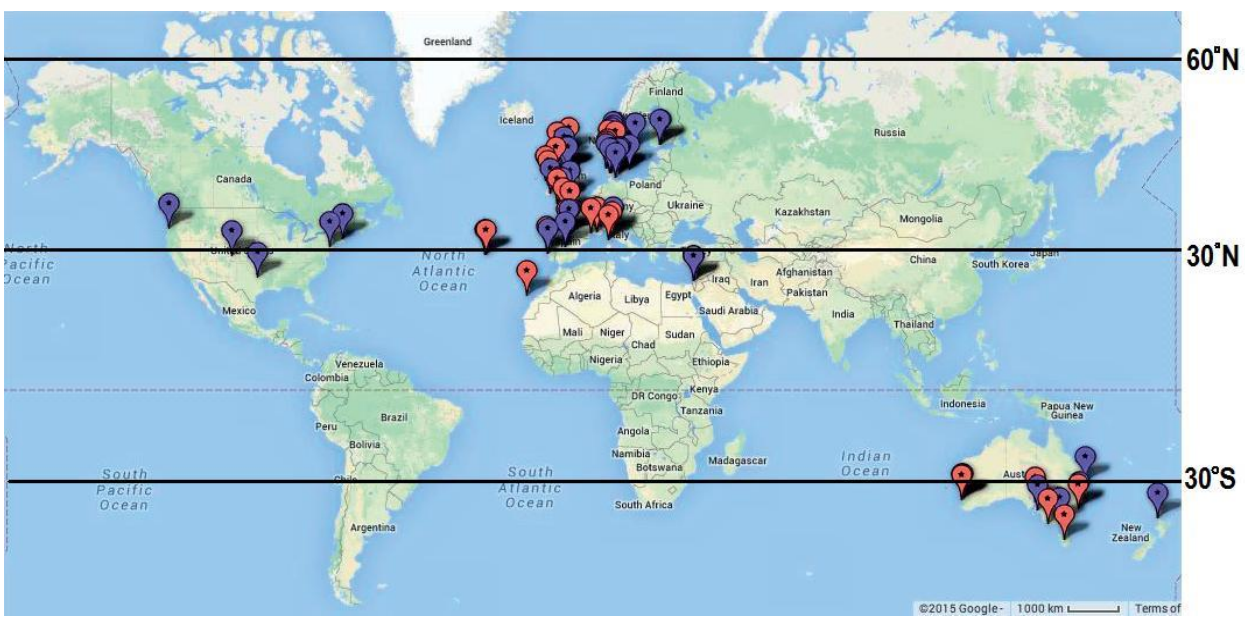

Fig. 2. Wave energy network. Purple markers: developers' headquarters; red markers: test sites and demonstration sites under development [8].

In recent years, several kinds of ocean power converter prototypes have been developed, according to the expertise of each inventing team and or specific issues from the local sea where it was designated [9-14]. These large numbers of prototypes and concepts indicated that the most suitable technology has not been defined to be applied for commercial purposes [9]. In fact, wave energy converters design is still in its infancy with significant research 
being devoted to quest for more efficient and reliable designs. So far, no typology has provided a clear advantage over others in term of efficiency, cost of production, and maintenance requirements, thus new devices continue to be developed [15]. Harnessing marine renewable energy such as wave energy requires a profound knowledge of the available resources and oceanographic conditions of the locality being considered for energy harvesting [16]. Moreover, when developing a wave energy harvester, it is important to design with the site of installation in mind. Different locations experience different wave conditions that may not yield successful results for a system that is not designed to accommodate the waves encountered [17].

Wave energy extraction is a hydrodynamic and mechanical process including complex wave phenomena (radiation and diffraction) and nonlinear oscillations, especially for the offshore wave energy extraction systems. A typical Wave Energy Converter (WEC) consists of two major sections; the Primary Interface (PI) and the Power Take Off (PTO). The PI is the part of the WEC responsible for harnessing energy from the sea waves and transforming it to mechanical energy (i.e. reciprocating or rotary motion of a shaft). The PTO convert the mechanical energy generated to a more easily transmittable form of energy, usually, but not always electrical energy.

In the WEC concept by [18], the PI (a buoy) and PTO was modelled on the principle of a mass-spring-damper vibrating system. Excitation force of the sea waves was assumed to be monochromatic for simplicity of modelling. Thus, the equation describing its motion, based on Newton's second law of motion, was given by:

$$
(M+A) \ddot{Z}+(B+C) \dot{Z}+(\rho g S) \mathrm{Z}=\mathrm{fe}
$$

where $\mathrm{M}$ is the mass (kg) of the buoy, $\ddot{Z}$ is the buoy's acceleration in heave; $A$ and $B$ are added mass $(\mathrm{kg})$ and radiation damping $(\mathrm{kg} / \mathrm{s})$, respectively; $C$ is PTO damping (that is, when acting as a generator), $\dot{Z}$ is buoy's velocity in heave $(\mathrm{m} / \mathrm{s}), \rho$ is the density of the sea water (in $\left.\mathrm{kg} / \mathrm{m}^{3}\right) ; \mathrm{g}$ is the acceleration due to gravity $\left(\mathrm{m} / \mathrm{s}^{2}\right) ; \mathrm{S}$ is the cross sectional area of the buoy at the water plane; $Z$ is buoy's displacement in heave $(\mathrm{m})$ and $f e$ is the excitation force from incident wave. Simulation of the WEC system in the time domain was executed using the Matrix Laboratory (MATLAB R2009a). The impute parameters, constituting the sea states, are described by both the significant wave height $\mathrm{H}_{\mathrm{s}}$ and the corresponding energy period $\mathrm{T}_{\mathrm{e}}$. The output parameters obtained from the simulations were buoy's displacements, velocity, acceleration, and force, as well as the WEC's instantaneous power output. Vallidation of a concept WEC numerical simulations via experimental testing of reduced scaled physical version or model of the WEC in wave tanks or flumes is an established proceedure in the field of WEC research and development, examples of which are $[6,10,14]$.

The focus of this paper is to report experimental validation of a concept wave energy converter as proposed by [18] that may facilitate the economical extraction of low amplitude ocean waves of the tropical regions for electricity generation.

\section{METHODOLOGY}

This section presents the methodology employed in the experimental validation of numerical simulation results for a concept wave energy converter to harness low amplitude waves by these authors [18]. In order to convert the physical dimensions represented by the laboratory scale model of the concept WEC to full scale dimensions used in the numerical simulations, the Froude scaling factors were applied. Froude scaling factor is a function of the linear scale ratio for individual physical parameters of interest in this study. The scale factor $(\lambda)$ for the experimental model is 19.5 which is the ratio of the concept WEC buoy's actual maximum horizontal extent to the modelled experimental buoy maximum horizontal extent.

\subsection{Description of the concept device}

The details of the concept are as contained in [18]. Briefly, the device is based on point absorber, which can operate in a wave climate characterized by low amplitude waves. The device consists of three main parts. The first part is a Wave Amplifying Device (WAD), meant to focus the incident wave into a narrow parallel wall channel in order to create a quasi- two dimensional waves with attendant magnification of the wave height, and thus the power content per unit length of wave crest in the throat. There is also a second part, which consists of a buoy (or several buoys in-line) floating in the throat section, with the buoy(s) to be connected to the Power Take Off (PTO) located on a platform mounted on a platform above the throat section. To constitute the third part of the device is the PTO. The concept WEC configuration and how it may be integrated to a port breakwater is as depicted in Figure 3. 
Integration of WECs to existing marine structures to minimize overall cost of construction is gaining traction [1921].

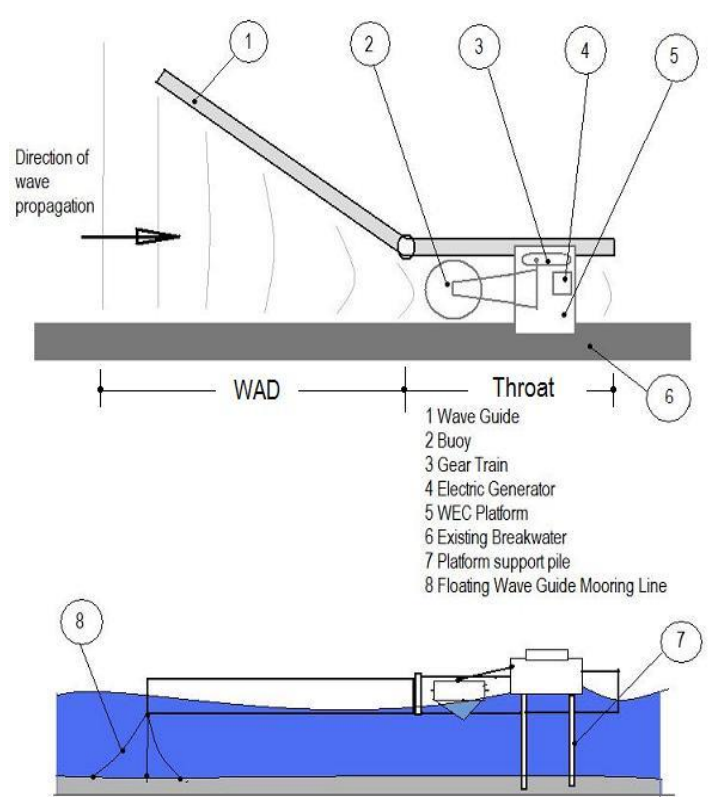

(a)

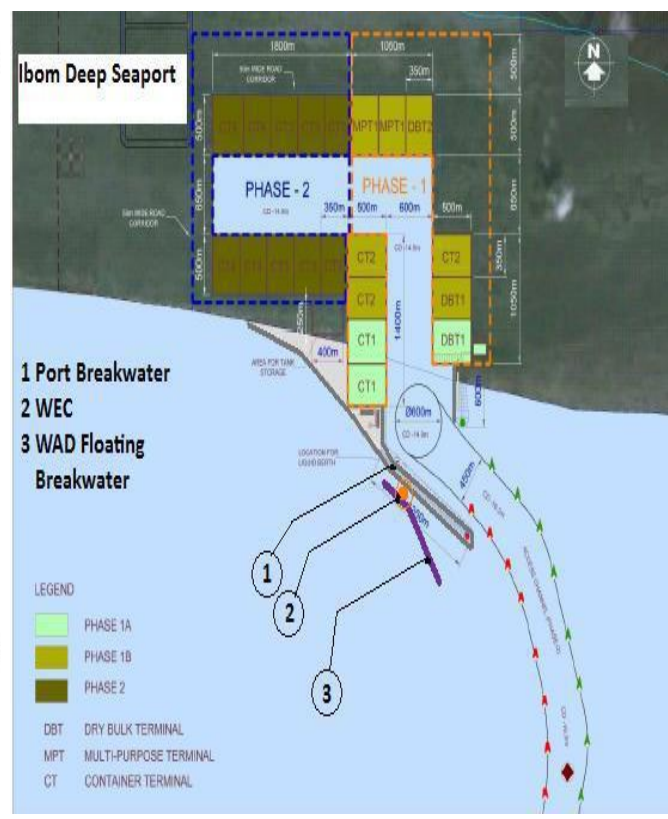

(b)

Fig. 3. (a) A schematic of the concept wave energy converter, (b) WEC as it may be integrated to a port breakwater [18].

\subsection{Instrumented wave flume}

The experimental validation of the WEC concept model was done using the water flume available at the Department of Mechanical Engineering, Osun State University, Osogbo, Nigeria. The flume was modified for use as a wave flume by installing a plunger type wave maker developed for the purpose, at one end of the flume and a glass beach at the opposite end. The flume has a length of $2.7 \mathrm{~m}$, a width of $0.21 \mathrm{~m}$ and a depth of $0.41 \mathrm{~m}$. The gradient of the installed glass beach was 1:6. The calm water depth for the tests was maintained at the beginning of each experimental run at $0.20 \mathrm{~m}$, this ensured that the generated waves do not spill over the walls of the flume while at the same time obtaining the maximum depth possible. The wave generator was capable of generating two dimensional monochromatic waves of height in the range 6 to $20 \mathrm{~mm}$ and periods 0.6 to 1.2 seconds. The waves were generated at three levels of wave heights and wave periods combinations $6 \mathrm{~mm}, 1.2 \mathrm{~s} ; 10 \mathrm{~mm}, 1.0 \mathrm{~s}$; and 20 $\mathrm{mm}, 0.6 \mathrm{~s}$, respectively.

Due to constraint imposed by the physical dimensions of the flume, it was considered impractical to install standard wave gauges into the wave path, since this resulted in significant distortion of the generated wave form. Instead, two 0.3 m length rules were attached to a side wall of the flume and high-speed video cameras were positioned perpendicular to the rules in order to record the wave motions. The video recordings were analyzed using a video software (Free Video to JPG Converter, version 5.0.78 build 328, available at http://www.dvdvideosoft.com) to reproduce the recorded video in still picture frames at one second's intervals. These frames were then studied for the extraction of wave height as a function of time as well as in determination of the wave period. Each experimental run lasted sixty seconds. This approach of wave height measurement was referred to in the literature as the visualization method and was similar to methods employed by [23] and described by [24].

\subsection{Wave amplification device optimum aperture angle}

In order, to establish the optimum aperture angle for the WEC's WAD reflector, a model wave amplification reflector and throat section were fabricated using plane glass. This was then mounted in an instrumented wave flume. The arrangement of the WAD reflector experimental model in the wave flume is as shown in Figure 4, while Figure 5 shows the picture of the WAD optimum aperture angle experimental set up. The wave guide/reflector angle was varied from $0^{\circ}$ (parallel to the flume side) to $90^{\circ}$ (perpendicular to the flume side) in a stepwise increment of $15^{\circ}$. For each position, the experiment was carried out under identical conditions of wave form and calm water depth. 
Video recording of the wave-WAD interaction based on aforementioned Visualization method were used to determine the incident wave height as well as the wave height at the throat section and the percentage wave magnification, defined here as ratio of throat wave height to incident wave height, was calculated for each aperture angle of interest. The percentage wave magnification was then plotted against the correspondent aperture angle; from the resulting graph, the optimal aperture angle was established.

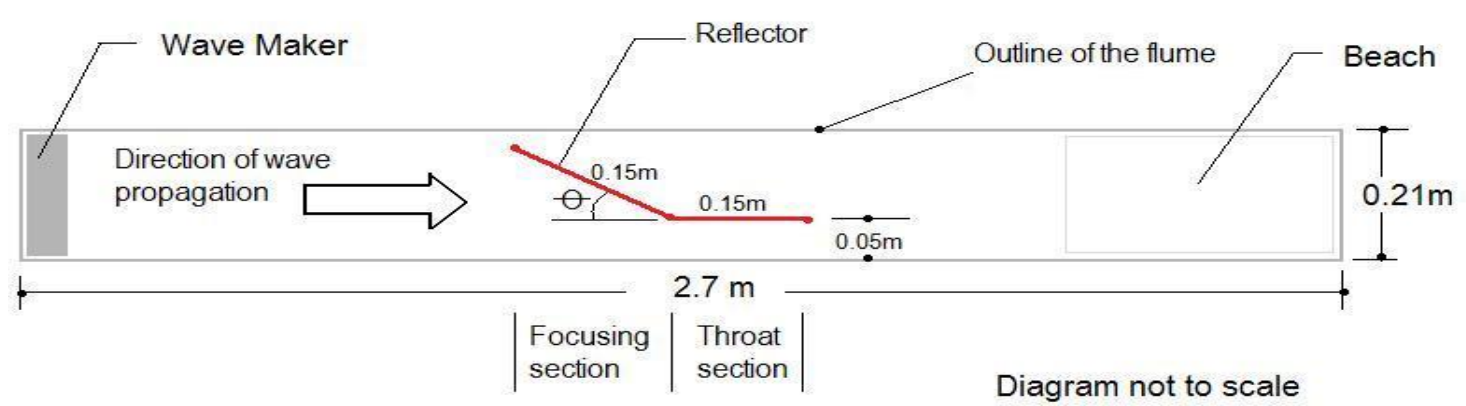

Fig. 4. Schematic of wave amplifying device model experimental set up in the wave flume (top view).

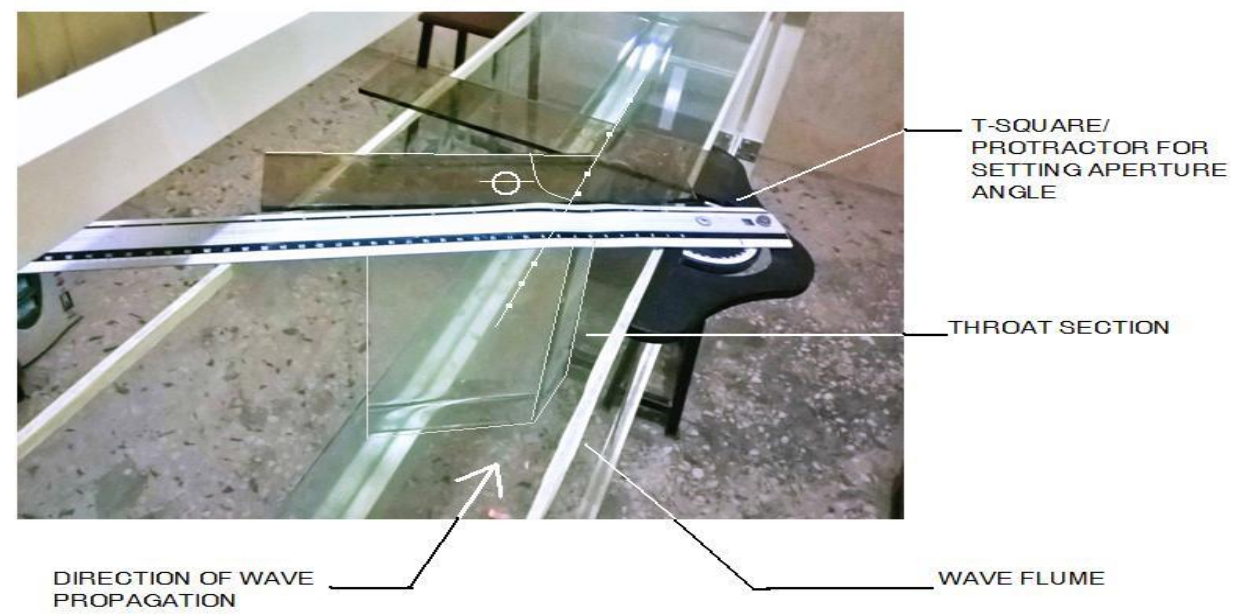

Fig. 5. Pictorial view of the experimental flume showing the positioning of the amplifying device model.

\subsection{Optimization of the primary interface}

Based on the established performance of buoy shapes as reported by [18], the cone- cylinder buoy and the concave wedge buoy were selected for further investigations. Geometrically similar model of each buoy form, using sponge foam was, fabricated at a scale of 1/19.5 of the actual size of the concept WEC buoy [18] with their dimensions as shown in Figure 6. Both designs have similar horizontal extent, draft, and weight, leaving the shape as the only physical difference. The two were tested in an instrumented wave flume using the same model PTO. They were both subjected to similar wave regimes in the wave flume.

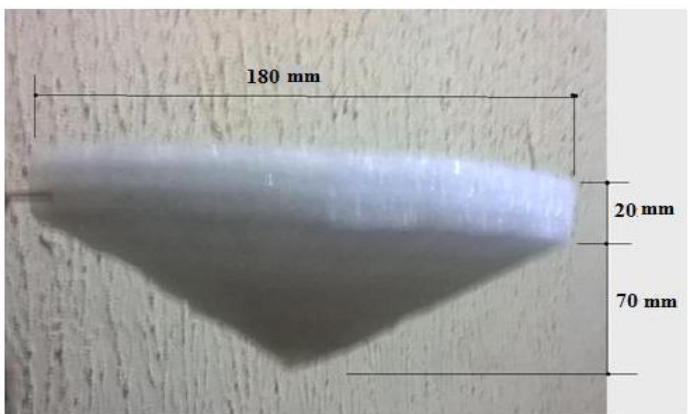

(a)

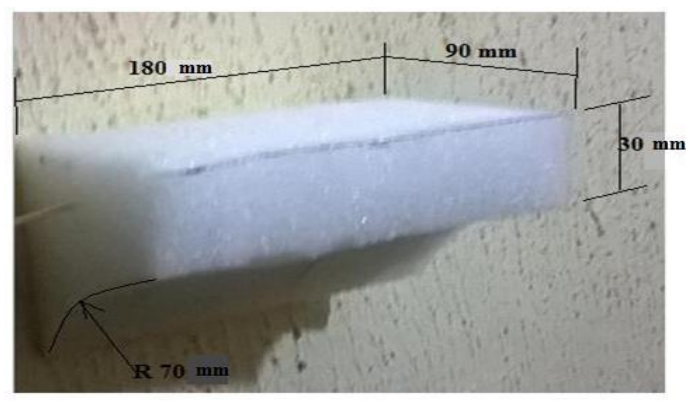

(b)

Fig. 6. Cone-cylinder sponge foam model (a), and Concave wedge buoy sponge foam model (b). 


\subsection{The scaled model of the concept wave energy converter}

The PTO consist of a rocker arm made from aluminum, the speed magnifying mechanism composed of a pulley and belt mechanism (real prototype, a compact gear train) with diametric ratio of seven between generator pulley and rocker arm shaft pulley, translating to seven times speed amplification, while the generator is a permanent magnet rotary generator (JL HRF-500TB 14415). By design, the buoys, when mounted on the rocker arm, were restricted to heave motion only. The model PTO was mounted on a wooden platform set across the wave flume, which provided a fixed frame of reference for the buoy's motion (Figure 7). In order, to convert the physical dimensions represented by the laboratory scale concept WEC model to full scale dimensions, the Froude scaling factors were applied. The scale factor $(\lambda)$ for the experimental model is 19.5 which is the ratio of the concept WEC buoy proposed maximum horizontal extent to the modeled experimental buoy maximum horizontal extent.

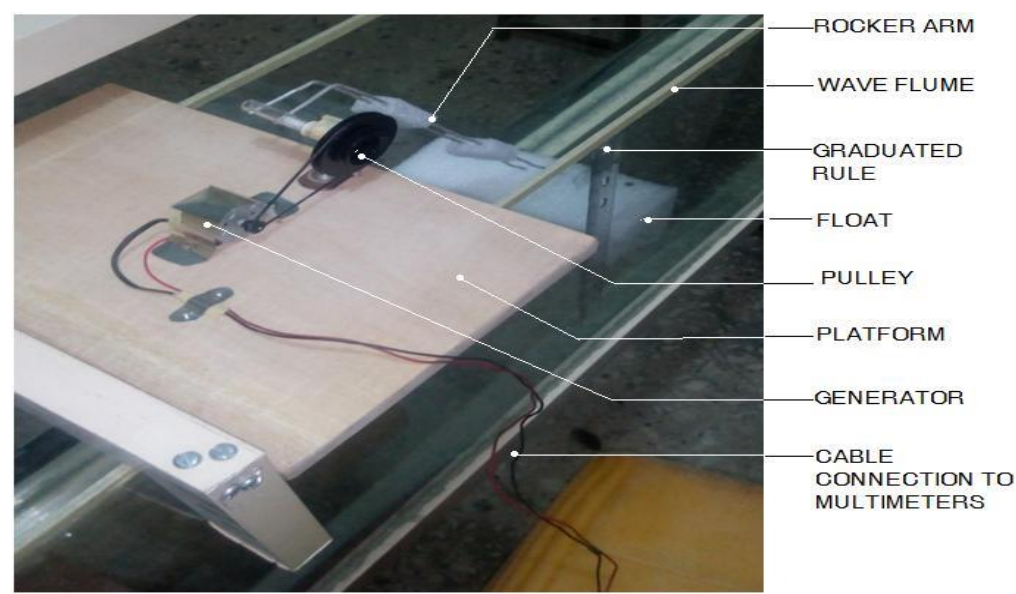

Fig. 7. Detail of the concept wave energy converter model power take off system.

\subsection{Experimental set up for validation of optimum buoy}

The schematic detail of the wave flume set up is as shown in Figure 8a while Figure 8b shows the pictorial view of the experimental set up. For the experimental runs the impute was the incident wave generated by the plunger type wave generator. Each experimental run lasted for 60 seconds and were repeated twice in order to ensure repeatability. The measured output parameters were the generator current (A) and voltage (V) which were measured using two multi-meters (DT 9205A for voltage measurement and Lutron DM-9093 for current). The output power was determine using equation (3) below.

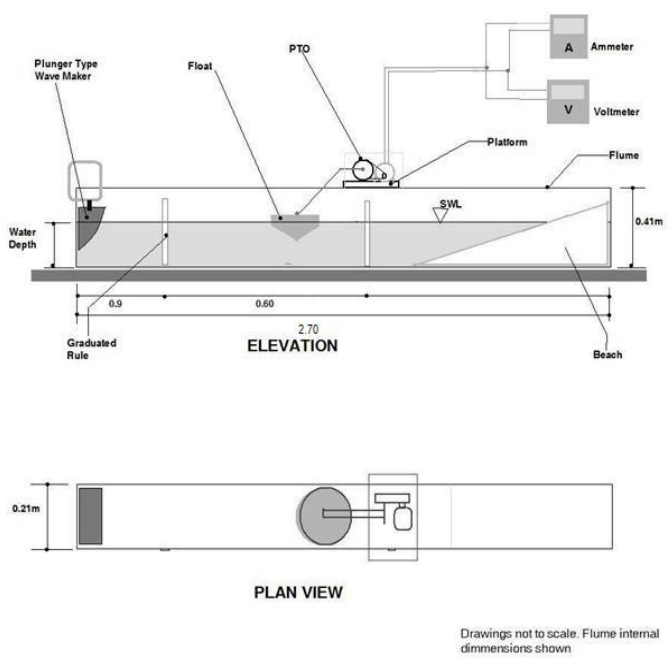

(a)

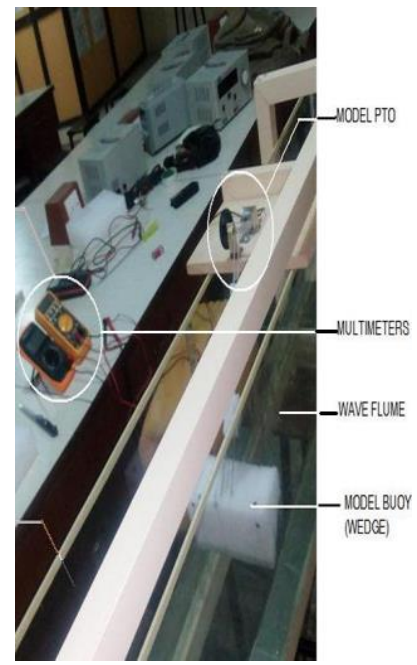

(b)

Fig. 8. Schematic of the Model WEC wave flume test experimental set up (a), pictorial view of the wave flume experimental set up (b). 


$$
P=I . V
$$

where $\mathrm{P}$ is the power generated in $\mathrm{W}, \mathrm{I}$ is the current in $\mathrm{A}$, and $\mathrm{V}$ is the emf in $\mathrm{V}$. The values for power generated thus acquired from current and voltage were then plotted against time using Microsoft Excel. Finally, the results for power generated by the model device were scaled up for comparison with the simulation results using Froude scaling.

\section{RESULTS AND DISCUSSION}

\subsection{Optimum aperture angle for wave amplification}

Figure 9 shows the relationship between the percentage wave amplification by the wave amplification device experimental model and its wave guide angle. From the figure, the optimum aperture angle for the wave guide is $45 \pm 2$ degree. Moreover, the greater the wave height of incident waves the greater the magnification. It is possible that the magnification can be up to $170 \%$ which translate to power content magnification of about three times of that of incident wave as the wave approaches the throat section of the device.

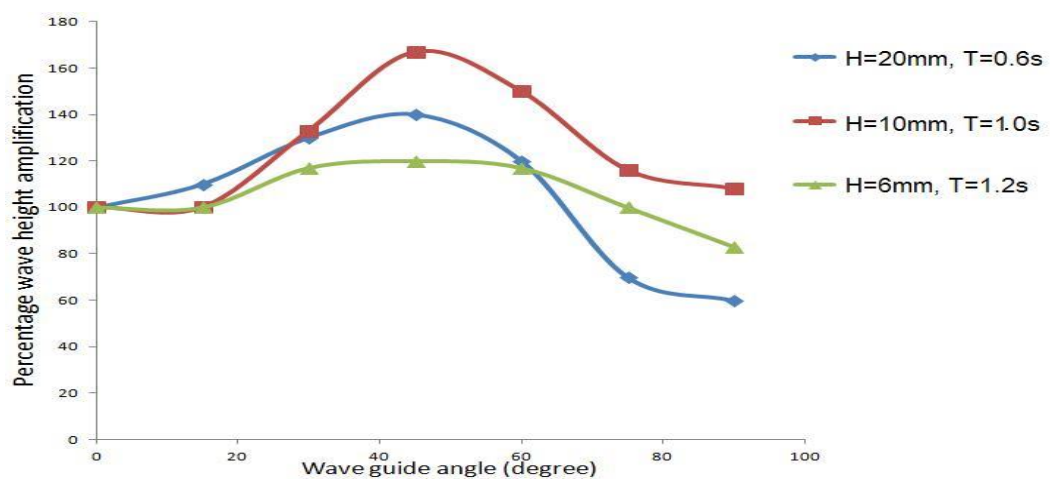

Fig. 9. Percentage wave height amplification for wave guide angle from zero to 90 degrees.

\subsection{Optimal buoy shape}

The measured electric power output for 60 seconds experimental runs for the concave wedge buoy under the three levels of wave parameters inputs are as presented in Figure 10, while that for Cone-cylinder buoy is as presented in Figure 11. The average electric power output for each type of buoys investigated in the experimental test of the scale model of the concept WEC is as presented in Figure 12. The figures reveals that the concave wedge buoy consistently gives out more power output than the cone-cylinder buoy under identical test conditions; hence the concave wedge buoy was established as the more efficient in term of power harnessing ability from wave. This observation is in line with theoretical proof that asymmetric buoys have greater energy conversion efficiency (100 $\%$ in theory) than symmetrical buoys (50\% in theory) $[18,24-26]$. Moreover, the generation of an electric power out-put by the scale model also serves as a proof of concept for the device.

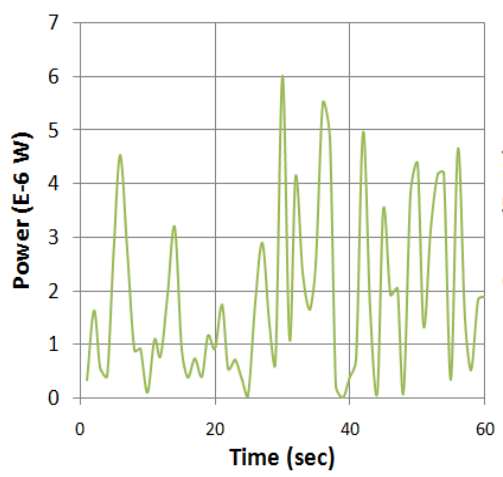

(a)

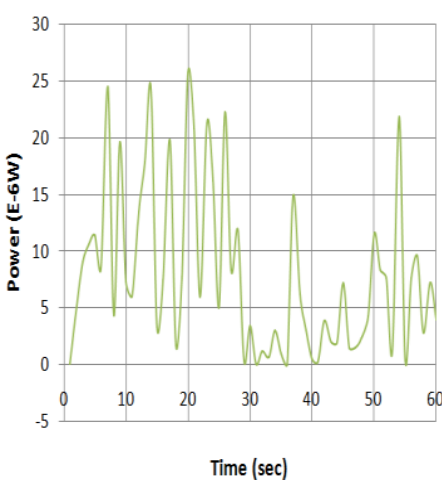

(b)

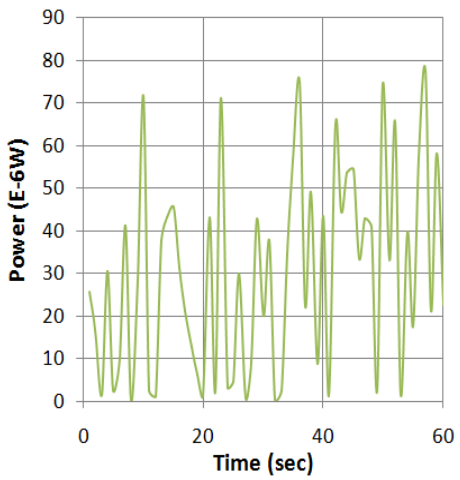

(c)

Fig. 10. Concave wedge buoy measured power for wave parameters (a) $\mathrm{H}=6 \mathrm{~mm}, \mathrm{~T}=1.2 \mathrm{~s}(\mathrm{~b}) \mathrm{H}=10 \mathrm{~mm}, \mathrm{~T}=$ $1.0 \mathrm{~s}$. and (c) $\mathrm{H}=20 \mathrm{~mm}, \mathrm{~T}=0.6 \mathrm{~s}$. 


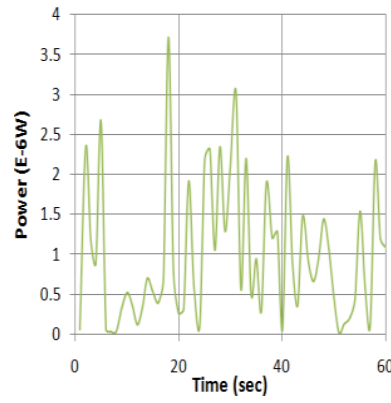

(a)

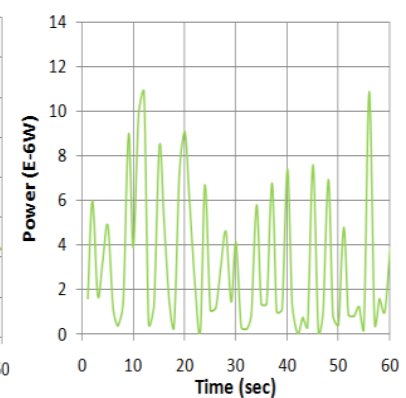

(b)

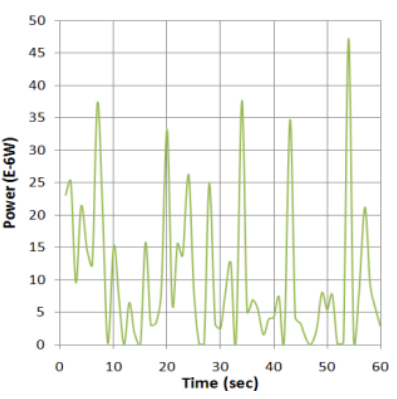

(c)

Fig. 11. Cone-cylinder buoy measured power for wave parameters (a) $\mathrm{H}=6 \mathrm{~mm}, \mathrm{~T}=1.2 \mathrm{~s}$ (b) $\mathrm{H}=10 \mathrm{~mm}, \mathrm{~T}=1.0$ s. and (c) $\mathrm{H}=20 \mathrm{~mm}, \mathrm{~T}=0.6 \mathrm{~s}$.

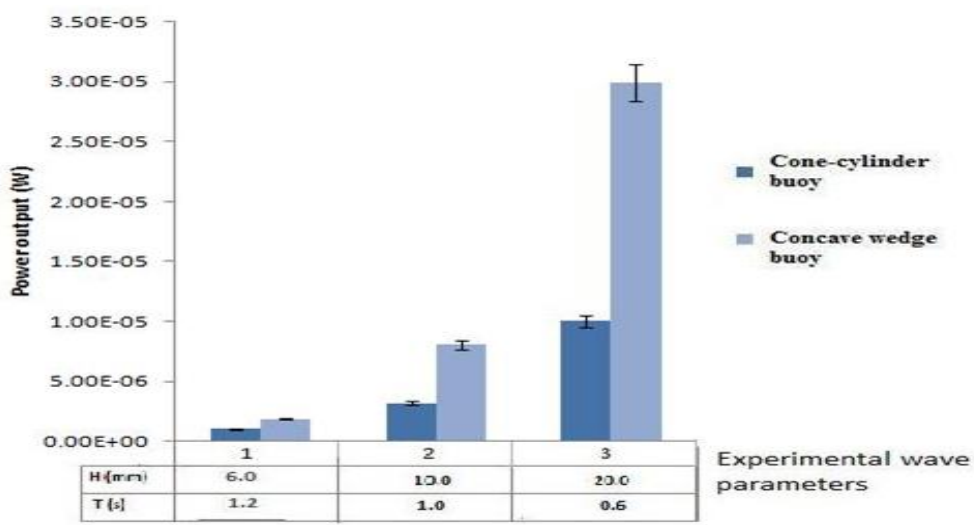

Fig. 12. Electric power output from three different wave regimes used in the experimental validation of the concept WEC for Cone-cylinder and concave wedge buoys.

\subsection{Validation of mathematical model}

Comparison between simulated results using the mathematical model employed by [18] to simulate the concept device and experimental power output for the concept wave energy converter under identical sea states for the two buoy shapes were as presented in Figure 13. The results of correlation between numerical simulations and experimental results (after Froude scaling) of the absorbed power per floater (in $\mathrm{kW}$ ) show that there is a significant relationships (at $r^{2}=0.978$ for cone-cylinder buoy and $r^{2}=0.973$ for concave wedge buoy), implying that the theoretical model developed by [18] is valid for power output prediction of the concept WEC. The difference in actual power output values observed between experimental and simulated results under identical condition, however, was due to the use of optimum damping coefficient for the simulated PTO, whereas, the experimental PTO generator was not run at maximum damping value due to practical constraints.

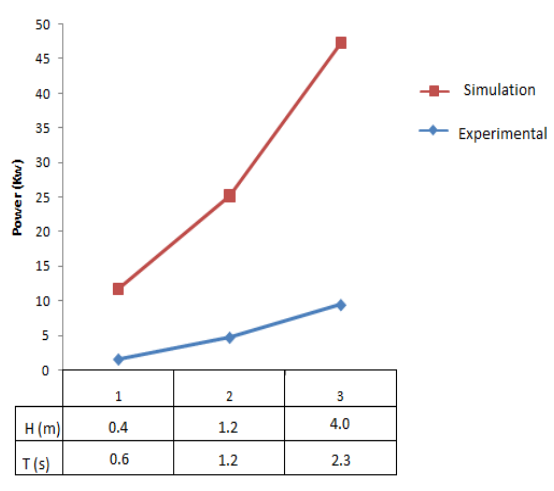

(a)

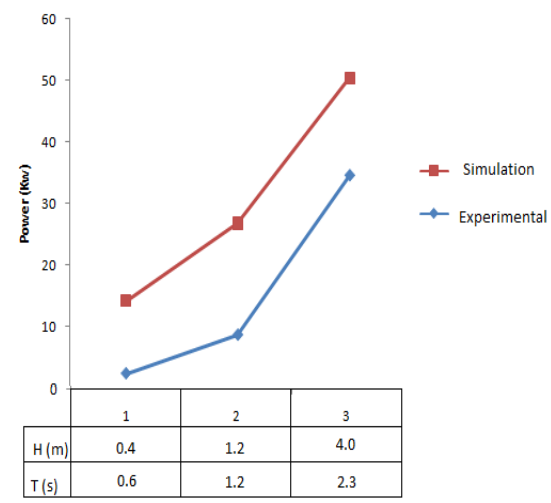

(b)

Fig. 13. Comparison between simulated and experimental power output for modeled wave energy converter WEC (a), Cone-cylinder buoy, (b) Concave wedge buoy. 


\section{CONCLUSIONS}

The following conclusions were drawn from the study:

- The concave wedge buoy is appropriate for power harnessing ability from wave.

- The optimum aperture angle for a single wave guide (for the wave amplification device) relative to the main axis of the device is $45 \pm 2$ degree, and wave height magnification of $170 \%$ which translated to power content magnification of about three times of that of incident wave is possible.

- The combination of the magnification of wave energy content of the incident waves coupled with efficient primary interface will make the device to tap economically the low amplitude waves characteristic of tropical waters.

\section{REFERENCES}

[1] Gunn, K., Stock,W.C., Quantifying the global wave power resources, Renewable Energy, vol. 44, 2012, p. 296-304.

[2] Pontes, M., Falcao, A., Ocean energies: Resources and utilisation, Proceedings of the $18^{\text {th }}$ Congress of the World Energy Council, Buenos Aires, Argentina, 2001.

[3] UNEP, Ocean energy potential of the west African Region, UNEP Regional Seas Reports and Studies, 1983, no. 30.

[4] Brooks, J., Wave energy conversion, Elsevier Ocean Engineering Book Series, Elsevier, Amsterdam, 2003.

[5] Thorpe, T.W., A brief review of wave energy, Harwell Laboratory, Energy Technology Unit,1999.

[6] Waters, R., Energy from ocean waves, full scale experimental verification of wave energy converter, Ph.D. Thesis, Uppsala University, Uppsala, 2008.

[7] Cruz, J. Ocean wave energy: current status and future perspectives, Springer, Berlin, Germany, 2008.

[8] Magagna, D., Uihlein, A., Ocean energy status report: Technology, market and economic aspects of ocean energy in Europe, European Commission Joint Research Centre, Institute for Energy and Transport, 2014.

[9] Beatty, S.J., Analysis and development of a three body heaving wave energy converter, Thesis, Department of Mechanical Engineering, University of British Columbia, Canada, 2007.

[10] Bhinder, M.A., Mingham, C.G., Causon, D.M., Rahmati, M.T., Aggidis, G.A., Chaplin, R.V., Numerical and experimental study of a surging point absorber wave energy converter, Proceedings of the 8th European Wave and Tidal Energy Conference, Uppsala, Sweden, 2009.

[11] Flocard, F., Finnigan, T.D., Experimental investigation of power capture from pitching point absorbers, Proceedings of the 8th European Wave and Tidal Energy Conference, Uppsala, Sweden, 2009.

[12] Ferreira1, R., Estefen, S., Ocean power conversion for electricity generation and desalinated water production, Marine and Ocean Technology, World Renewable Energy Congress, Linkoping, Sweden, 2011.

[13] Foster, J.W., Ghorbani, R., Garambois, P., Jonson, E., Karlsson, S., Development of a low cost point absorber wave energy converter for electric mobility, Marine and Ocean Technology, World Renewable Energy Congress, Linkoping, Sweden, 2011.

[14] Bosma, B., On the design, modelling, and testing of ocean wave energy converters, Ph.D dissertation submitted to School of ElectricalEngineering and Computer Science, Oregon State University, Corvallis, Oregon, USA, 2013.

[15] Falcao, A.F., Wave energy utilization: a review of the technologies, Renewable Sustainable Energy Review, vol. 14, no. 3, 2010, p. 899-918.

[16] Osorio, A., Agudelo, P., Correa, J., Otero, L., Ortega, S., Hernendez, J., Restrepo, J., Building a road map for the implementation of marine renewable energy in Colombia, Proceedings of OCEANS 2011 IEEE, Spain, 2011. [17] Helkin, S.A., Design and optimization of a wave energy harvester utilizing a flywheel energy storage system, Thesis, Department of Mechanical, Materials, and Aerospace Engineering, College of Engineering and Computer Science, University of Central Florida, Orlando, Florida, 2009.

[18] Kayode, O., Koya, O.A., Ajewole, T.O., Determination of the optimal buoy shape for a concept wave energy converter to harness low amplitude sea waves using numerical simulation, International Journal of Marine Engineering Innovation and Research, vol. 4, no. 3, 2019, p. 164-173.

[19] Ning, D., Zhao, X., Goteman, M., Kang, H., Hydrodynamic performance of a pile-restrained WEC-type floating breakwater: an experimental study, Renewable Energy, vol. 95, 2016, p. 531-541.

[20] Zheng, S., Zhang, Y., Wave diffraction and radiation by multiple rectangular floaters, Journal of Hydraulic Research, vol. 54, no. 1, 2016, p. 102-115.

[21] Zhao, X., Ning., D., Zhang, C., Liu, Y., Kang, H., Analytical study on an oscillating buoy wave energy converter integrated into a fixed box-type breakwater, Mathematical Problems in Engineering, vol. 2017, 2017, p. $1-9$. 
[22] Sarlak, H., Seif, M.S., Abbaspour, M., Experimental investigation of offshore wave buoy performance, Journal of Marine Engineering, vol. 6, no. 11, 2010, p. 1-11.

[23] Viriyakijja, K., Chinnarasri, C., Wave flume measurement using image analysis, Aquatic Procedia, vol. 4, 2015, p. 522-531.

[24] Falnes, J., A review of wave-energy extraction, Marine Structures, vol. 20, 2007, p. 185-201.

[25] Madhi, F., Sinclair, M.E., Yeung, R.W., The Berkeley Wedge: an asymmetrical energy-capturing floating breakwater of high performance, Marine Systems and Ocean Technology, vol. 9, no. 1, 2014, p. 5-16.

[26] Hardisty, J., Experiments with point absorbers for wave energy conversion, Journal of Marine Engineering and Technology, vol. 11, no. 1, 2012, p. 51-62. 